\title{
FATORES DE ESTRESSE ACADÊMICO: REPERCUSSÕES NA QUALIDADE DE SONO E DE VIDA DE ESTUDANTES DO ÚLTIMO ANO DA GRADUAÇÃO EM ENFERMAGEM
}

\author{
Sandra Soares Mendes ${ }^{1}$ \\ Milva Maria Figueiredo De Martino 2 \\ ${ }^{1}$ Doutoranda da Faculdade de Enfermagem - UNICAMP \\ ${ }^{2}$ Professora Colaboradora em Enfermagem - UNICAMP
}

INTRODUÇÃO: No último ano da graduação há fatores que podem potencializar o estresse, além dos aspectos acadêmicos, os alunos podem vivenciar sentimento de insegurança, inexperiência e competitividade do mercado de trabalho. OBJETIVO: Identificar os fatores de estresse do ambiente acadêmico e relacionar com o sono e a qualidade de vida. MÉTODO: Estudo transversal descritivo, e quantitativo. Participaram 55 discentes do último ano da graduação em enfermagem, de uma instituição privada na cidade de Poços de Caldas, Minas Gerais, entre maio e junho de 2018. Para análise dos dados foi feita estatística descritiva e coeficiente de correlação de Spearman. A pesquisa foi aprovada pelo Comitê de Ética em Pesquisa sob no 2.466.314. Aplicaram-se um questionário para caracterização sócio demográfica, o instrumento Escala para Avaliação de Estresse em Estudantes de Enfermagem (AEEE), Questionário Índice de Qualidade do Sono de Pittsburgh (PSQI) e o Questionário WHOQOLbref. RESULTADOS: A média de idade foi 32,09 anos, $80 \%$ sexo feminino e $74,54 \%$ trabalhavam. A correlação entre o escore total do PSQI e os domínios da escala $A E E E$, demonstrou uma relação positiva e forte para o domínio gerenciamento de tempo $(r=0,54 ; p<0,001)$, moderada para realização das atividades práticas $(r=0,38 ; p=0,003)$, comunicação profissional $(r=0,34$; $p=0,009)$, formação profissional $(r=0,35 ; p=0,007)$, atividade teórica $(r=0,44$; $p<0,001)$ e fraca para o domínio ambiente $(r=0,20 ; p=0,127)$. Foram observadas uma correlação negativa e de forte magnitude dos domínios físico, psicológico e de ambiente do Whoqol com o domínio gerenciamento de tempo do AEEE, bem como correlação negativa e moderada desses mesmos domínios do Whoqol com os seguintes domínios do AEEE: realização de atividades práticas, comunicação profissional, ambiente, formação profissional e atividade teórica. CONCLUSÃO: A medida que houve aumento da exposição aos fatores do 
estresse acadêmico relacionado às dificuldades de gerenciamento do tempo, da vida acadêmica, pessoal, familiar e social, bem como as novas situações vivenciadas em campo de estágio e aspectos relacionados a futura vida profissional, houve uma maior potencialidade para aumentar o escore do PSQI e diminuir os escores dos domínios do Whoqol, podendo levar a redução da qualidade do sono e de vida dos estudantes.

Palavras-chave: Estresse psicológico. Sono. Qualidade de vida. 